\title{
Proprioceptive use and sit-to-stand-to-sit after lumbar microdiscectomy: The effect of surgical approach and early physiotherapy
}

\author{
Lotte Janssens ${ }^{\mathrm{a}, \mathrm{b}, *}$, Simon Brumagne ${ }^{\mathrm{a}}$, Kurt Claeys ${ }^{\mathrm{a}, \mathrm{c}}$, Madelon Pijnenburg ${ }^{\mathrm{a}, 1}$, Nina Goossens ${ }^{\mathrm{a}}$, \\ Sofie Rummens ${ }^{\mathrm{d}}$, Bart Depreitere ${ }^{\mathrm{e}}$ \\ ${ }^{a}$ KU Leuven Department of Rehabilitation Sciences, Leuven, Belgium \\ ${ }^{\mathrm{b}}$ Hasselt University, Biomedical Research Institute, Diepenbeek, Belgium \\ ${ }^{\mathrm{c}}$ KU Leuven Department of Rehabilitation Sciences, Campus Brugge, Bruges, Belgium \\ ${ }^{\mathrm{d}}$ Department of Physical Medicine and Rehabilitation, University Hospitals Leuven, Leuven, Belgium \\ e Department of Neurosurgery, University Hospitals Leuven, Leuven, Belgium
}

\section{A R T I C L E I N F O}

\section{Article history:}

Received 27 July 2015

Accepted 29 December 2015

\section{Keywords:}

Low back pain

Proprioception

Postural control

Microdiscectomy

Physiotherapy

Sit to stand

\begin{abstract}
A B S T R A C T
Background: Individuals with non-specific low back pain show decreased reliance on lumbosacral proprioceptive signals and slower sit-to-stand-to-sit performance. However, little is known in patients after lumbar microdiscectomy.

Methods: Patients were randomly assigned into transmuscular $(n=12)$ or paramedian lumbar surgery $(n=13)$. After surgery, the same patients were randomly assigned into individualized active physiotherapy starting 2 weeks after surgery $(n=12)$ or usual care $(n=13)$. Primary outcomes were center of pressure displacement during ankle and back muscles vibration (to evaluate proprioceptive use), and the duration of five sit-to-stand-to-sit movements, evaluated at 2 (baseline), 8 and 24 weeks after surgery.

Findings: Two weeks after surgery, all patients showed smaller responses to back compared to ankle muscles vibration $(P<0.05)$. Patients that underwent a transmuscular surgical procedure and patients that received physiotherapy switched to larger responses to back muscles vibration at 24 weeks, compared to 2 weeks after surgery $(P<0.005)$, although not seen in the paramedian group and usual care group $(P>0.05)$. Already 8 weeks after surgery, the physiotherapy group needed significantly less time to perform five sit-to-stand-to-sit movements compared to the usual care group $(P<0.05)$.

Interpretation: Shortly after lumbar microdiscectomy, patients favor reliance on ankle proprioceptive signals over lumbosacral proprioceptive reliance to maintain posture, which resembles the behavior of patients with non-specific low back pain. However, early active physiotherapy after lumbar microdiscectomy facilitated higher reliance on lumbosacral proprioceptive signals and early improvement of sit-to-stand-to-sit performance. Transmuscular lumbar surgery favoured recovery of lumbosacral proprioception 6 months after surgery. Clinical Trial Number: NCT01505595
\end{abstract}

(c) 2016 Elsevier Ltd. All rights reserved.

\section{Introduction}

Up to $78 \%$ of the low back pain (LBP) patients relapse into a pain episode (Airaksinen et al., 2006). When persistent nerve root compression caused by disc herniation is present, lumbar microdiscectomy is recommended. Despite the high success rate of first-time lumbar

\footnotetext{
* Corresponding author at: Department of Rehabilitation Sciences, KU Leuven, Tervuursevest 101, Box 1501, Leuven 3001, Belgium.

E-mail addresses: LotteJanssens@faber.kuleuven.be (L. Janssens),

Simon.Brumagne@faber.kuleuven.be (S. Brumagne), Kurt.Claeys@faber.kuleuven.be

(K. Claeys), m.pijnenburg@fontys.nl (M. Pijnenburg), Nina.Goossens@kuleuven.be

(N. Goossens), Sofie.Rummens@uzleuven.be (S. Rummens),

Bart.Depreitere@med.kuleuven.be (B. Depreitere).

1 Present address: Department of Allied Health Professions, Fontys University of Applied Sciences, Eindhoven, The Netherlands.
}

microdiscectomy in terms of neural repair, residual functional complaints are not infrequent (Loupasis et al., 1999). Short term after surgery, lumbar microdiscectomy provides more rapid recovery than non-operative treatment, but no difference in functionality and pain is found in the long run (Jacobs et al., 2011b; Loupasis et al., 1999). The underlying mechanisms of these residual complaints remain largely unknown, although identification of these factors is listed as a high research priority in this research area (Costa et al., 2013; McGregor et al., 2006).

Optimal postural control is indispensable to carry out functional activities. An essential daily functional activity, which necessitates postural control (Lord et al., 2002), is the sit-to-stand-to-sit (STSTS) task (Dall and Kerr, 2010). In LBP patients, the STSTS task is more energy demanding (Shum et al., 2009) and associated with altered movement patterns (Jacobs et al., 2011a). Decreased postural control is a potential 
factor in the etiology of recurrent non-specific LBP. A possible mechanism for this is reduced lumbosacral proprioception. When lumbosacral proprioceptive signals lose reliability due to LBP, individuals are likely to rely dominantly on ankle proprioceptive signals, irrespective of the postural demands (Brumagne et al., 2008; Claeys et al., 2011, 2015). Consensus on the effect of lumbar surgery on postural control is lacking. One study showed that individuals recovered the ability to control their postural sway in the early postoperative period (Sipko et al., 2010), although another study showed no full recovery 3 months after surgery (Leinonen et al., 2003). Even 3 years after surgery, postural control was still impaired, even in those who were pain-free (Bouche et al., 2006).

Enhancing postural control may play a role in the resolution of longterm residual functional complaints after lumbar surgery. However, no studies exist on the effect of rehabilitation on postural control after lumbar microdiscectomy. Active over passive treatment after lumbar surgery (Carragee et al., 1999), and an early start of physiotherapy is suggested (Hebert et al., 2010; Millisdotter and Strömqvist, 2007). However, utilization of these parameters appears to be low (Williamson et al., 2007), and significant variability in routine treatment and advice in outpatient care after surgery is observed (Karikari and Isaacs, 2010; Williamson et al., 2007). Moreover, until now only low-quality evidence of physiotherapy after lumbar microdiscectomy was found, due to the lack of individualized and targeted care (Oosterhuis et al., 2014).

Also, different lumbar surgery procedures have been used. Since classic paramedian surgical approaches require more muscle damage, minimally invasive transmuscular approaches have been developed, although clinical evidence is discussed nowadays (Kamper et al., 2014). Adequate function of the paraspinal trunk muscles, potentially to be damaged by surgery, is indispensable for postural control (Hides et al., 1996). However, the influence of the transmuscular versus paramedian approach of lumbar microdiscectomy on lumbosacral proprioceptive acuity has not been investigated yet. Taken together, it remains unknown whether the impaired postural control in lumbar microdiscectomy patients might be attributed to altered proprioceptive use, and whether it affects STSTS performance. Moreover, it is unclear whether these parameters are affected by surgical technique and physiotherapy.

Optimizing clinical outcomes after lumbar surgery is recognized as a priority for future research (McGregor et al., 2006). Identifying specific and adaptable underlying mechanisms can support the development of tailored interventions (van der Windt and Dunn, 2013). Therefore, the first aim of this study was to evaluate the specific use of proprioception during postural control after two types of lumbar microdiscectomy. We hypothesized that proprioceptive use during postural control and STSTS performance are impaired after lumbar microdiscectomy, and that a transmuscular approach creates less impairment than a paramedian approach. The second aim was to confirm the presence of these impairments after lumbar microdiscectomy by investigating the effect of early active individualized physiotherapy on it. We hypothesized that early active individualized physiotherapy enables lumbar microdiscectomy patients to increase reliance on lumbosacral, rather than ankle, proprioceptive signals during postural control and improves STSTS performance. This proof-of-principle would confirm the presence of proprioceptive impairments as one underlying mechanism of the residual complaints after lumbar microdiscectomy.

\section{Methods}

\subsection{Participants}

One hundred and nine patients after lumbar microdiscectomy were assessed for eligibility by the neurosurgeon. Patients were included if their age ranged between 18 and 60 years old, if they had a first-time single-level (L4-L5 or L5-S1) paramedian disc herniation indicative for surgical intervention and if they reported a score of at least $10 \%$ on the Oswestry Disability Index (version 2.1.a, adapted Dutch version)
(ODI-2) after surgery (Fairbank and Pynsent, 2000). Participants were excluded from the study in case of previous spinal surgery, median disc herniation, vestibular or neurological disorders, significant neurological deficit (paresis $>4 / 5$ ), lower limb problems, or work accident. Twenty-five eligible participants were included and four independent groups were created (Fig. 1): transmuscular surgery + physiotherapy $(n=6)$, transmuscular surgery + usual care $(n=6)$, paramedian surgery + physiotherapy $(n=6)$, and paramedian surgery + usual care $(n=7)$. These groups were clustered by a mixed group design because power analysis (Brumagne et al., 2008; Claeys et al., 2011, 2012, 2015; Janssens et al., 2015) revealed a sample size of 11 participants to provide adequate power ( 0.80 with a two-tailed alpha level of 0.05 ) to detect a clinically relevant difference in center of pressure displacement on unstable support surface (our primary outcome measure with smallest effect size). First, they were randomly allocated (blinded by computer algorithm) for surgical approach into a transmuscular group ( $n=12 ; 7$ women $/ 5$ men) and paramedian group ( $n=13 ; 7$ women/6 men). Subsequently, the same patients were re-allocated into a physiotherapy group ( $n=12 ; 7$ women/5 men) and a usual care group ( $n=13 ; 7$ women/6 men). Before surgery, all participants completed a number of questionnaires. Severity of pain was scored by the Numerical Rating Scale (NRS) (Jensen et al., 1986). The FearAvoidance Beliefs Questionnaire (FABQ) was completed to identify to which extent fear of LBP affects their work and physical activity (Waddell et al., 1993). The Hospital Anxiety and Depression Scale (HADS) was completed to assess anxiety and depression (Zigmond and Snaith, 1983). The Pain Catastrophizing Scale (PCS) was completed to assess the amount of catastrophizing associated with their LBP (Sullivan et al., 1995). Finally, motivation for study participation was scored on the Numerical Rating Scale (NRS) (0-10).

The participants' characteristics before lumbar microdiscectomy are summarized in Table 1 . All participants gave their written informed consent. The study conformed to the principles of the Declaration of Helsinki (1964) and was approved by the local Ethics Committee of Biomedical Sciences, Katholieke Universiteit Leuven and registered at www.clinicaltrials.gov (NCT01505595).

\subsection{Study design}

The objectives of this study were, first, to investigate proprioceptive use during postural control and STSTS performance after two surgical approaches of lumbar microdiscectomy and, second, to investigate the effect of early active individualized physiotherapy on these parameters. These primary outcomes were evaluated at 2 (baseline), 8 and 24 weeks after surgery. These primary outcomes were not evaluated before surgery due to pre-surgery disability. Secondary outcomes were severity of pain and LBP-related disability and kinesiophobia, evaluated before and 2 (baseline), 8, 24 weeks, and 1 year after surgery. Global perceived effect of the intervention (0-10), duration of work absence (days), and recurrence rate were scored 1 year after surgery. Fig. 1 displays the flowchart of the study.

\subsection{Materials}

\subsubsection{Surgical procedures of lumbar microdiscectomy}

2.3.1.1. Transmuscular approach. A $2-\mathrm{cm}$ incision was made at two $\mathrm{cm}$ from the midline at the spinal level of the disc herniation (L4-L5 or L5-S1). A Kirschner pin was inserted and directed toward the facet joint, confirmed by fluoroscopy. Subsequently, dilators were introduced over the Kirschner pin. A final tubular retractor ( $18 \mathrm{~mm}$ outer diameter, METRx system, Medtronic) was inserted over the sequential dilators and seated firmly on the bony anatomy. The tubular retractor was then attached to a fixation arm, connected with the surgical table. Using microscope magnification, the caudal part of the lamina was removed, and the ligamentum flavum was opened. The thecal sac and 


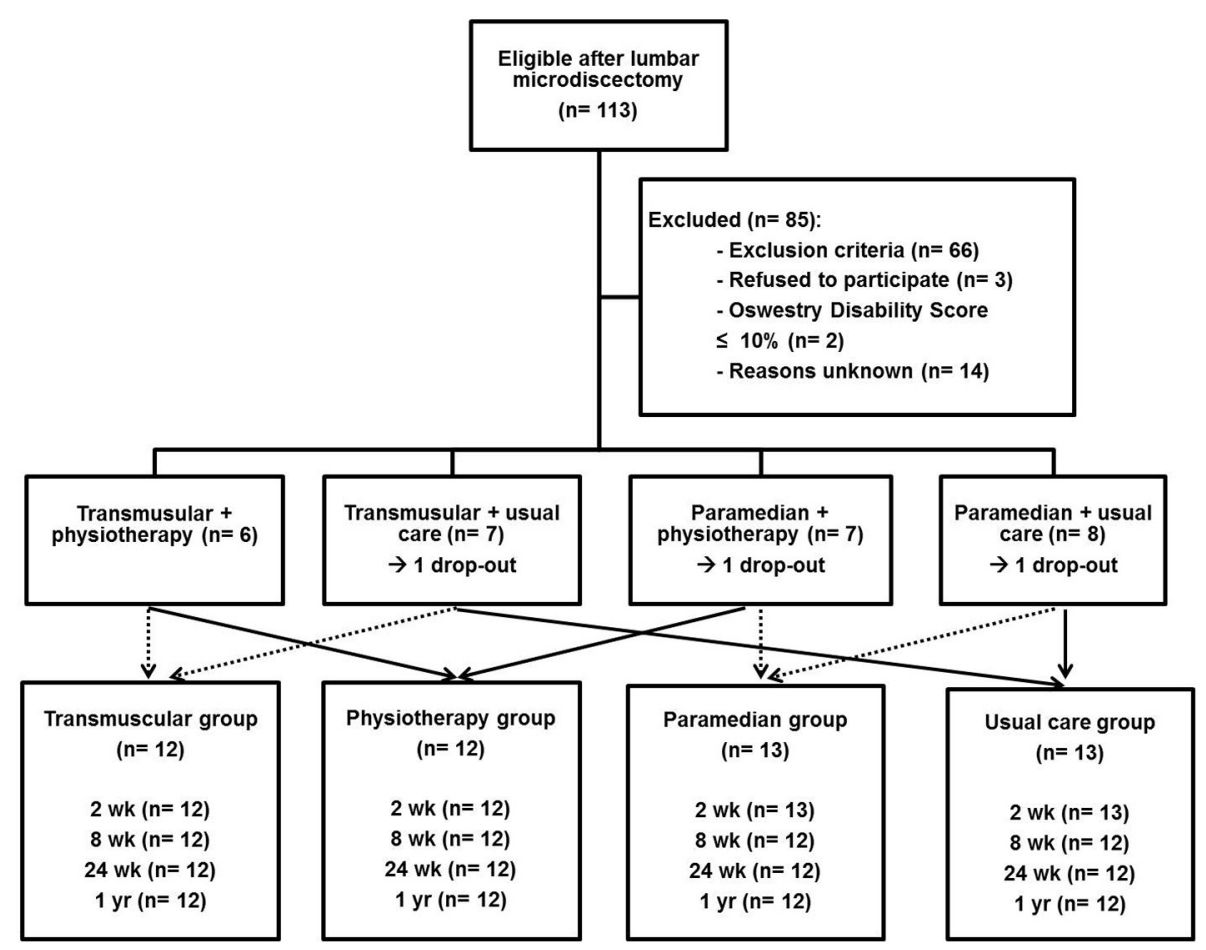

Fig. 1. Flowchart of the study.

nerve root were retracted medially and the herniated material was removed.

2.3.1.2. Paramedian approach. A 3- to $4-\mathrm{cm}$ incision was made at the midline at the spinal level of the disc herniation (L4-L5 or L5-S1), confirmed by fluoroscopy. The skin was incised in the midline, and the fascia thoracolumbalis was incised at a paramedian location. The lumbosacral muscles were detached from their insertion at the spinous process and ligamentum interspinosum. A speculum was inserted into the incision, and the caudal part of the lamina was removed by Kerrison rongeurs under microscope magnification. The ligamentum flavum was opened. The thecal sac and the nerve root were retracted medially and the herniated material was removed.

\subsubsection{Physiotherapy}

The individual physiotherapy started 2 weeks after surgery at the Department of Physical Medicine and Rehabilitation (University Hospitals Leuven, Belgium). The program was based on a history taking and physical examination. The physiotherapy focused on individualoriented patient education, ergonomics and motor control exercises, and, if required, segmental spinal mobilizations and neurodynamics.
Examples of specific physiotherapy techniques were correction of sitting posture, isolated and low-intensity recruitment of the deep abdominal and back muscles (Tsao and Hodges, 2008), active and passive neurodynamic sliders of the sciatic nerve (Shacklock, 1995), and segmental mobilization of the thoracolumbar spine. The emphasis on the early and active component of physiotherapy was based on previous evidence (McGregor et al., 2006). Eight to 15 sessions of physiotherapy were administered during a maximum period of 12 weeks. The usual care group received only basic ergonomic advice, the advice to stay active and a restriction of physiotherapy for at least 12 weeks.

\subsubsection{Primary outcome measures}

2.3.3.1. Proprioceptive use during postural control. The experimental setup is demonstrated in Fig. 2. Postural sway characteristics were assessed by center of pressure displacement with a 6-channel force plate (Bertec, $\mathrm{OH}, \mathrm{USA}$ ). Force plate signals were sampled at $500 \mathrm{~Hz}$ with a Micro1401 data acquisition system and Spike2 software (Cambridge Electronic Design, UK). Local muscle vibration was used to investigate the role of proprioception in postural control. Muscle vibration $(60 \mathrm{~Hz}, 0.5 \mathrm{~mm})$ is a powerful stimulus of muscle spindle Ia

Table 1

Participants' characteristics before lumbar microdiscectomy

\begin{tabular}{|c|c|c|c|c|c|c|}
\hline & Transmuscular $(n=12)$ & Paramedian $(n=13)$ & $P$-value & Physiotherapy $(n=12)$ & Usual care $(n=13)$ & $P$-value \\
\hline Age (year) & 49 (10) & $43(9)$ & 0.153 & $46(11)$ & $46(8)$ & 0.996 \\
\hline Height $(\mathrm{cm})$ & $173(10)$ & $172(11)$ & 0.872 & $174(10)$ & $171(11)$ & 0.485 \\
\hline Weight (kg) & 75 (15) & 79 (16) & 0.586 & 79 (16) & 75 (15) & 0.587 \\
\hline BMI $\left(\mathrm{kg} / \mathrm{m}^{2}\right)$ & $25(3)$ & $26(4)$ & 0.376 & $26(4)$ & $26(3)$ & 0.802 \\
\hline ODI-2 (\%) & $23(10)$ & $24(8)$ & 0.793 & $25(6)$ & $22(11)$ & 0.485 \\
\hline NRS pain & $7.1(2.6)$ & $8.3(1.5)$ & 0.114 & $7.6(2.3)$ & $7.6(2.3)$ & 1.000 \\
\hline FABQ & $38(12)$ & $45(10)$ & 0.183 & $41(10)$ & $42(12)$ & 0.844 \\
\hline HADS & $16(6)$ & $14(7)$ & 0.444 & $14(6)$ & $15(7)$ & 0.881 \\
\hline PCS & $29(10)$ & $26(9)$ & 0.561 & 27 (13) & $28(7)$ & 0.892 \\
\hline Motivation & $8.2(1.7)$ & $9.2(1.1)$ & 0.188 & $8.5(1.9)$ & $8.8(1.2)$ & 0.558 \\
\hline
\end{tabular}

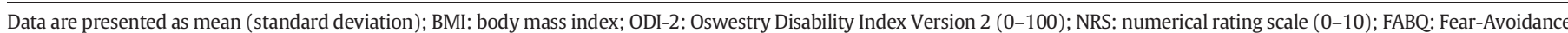
Beliefs Questionnaire (0-66); HADS: Hospital Anxiety and Depression Scale (0-21); PCS: Pain Catastrophizing Scale (0-52). 


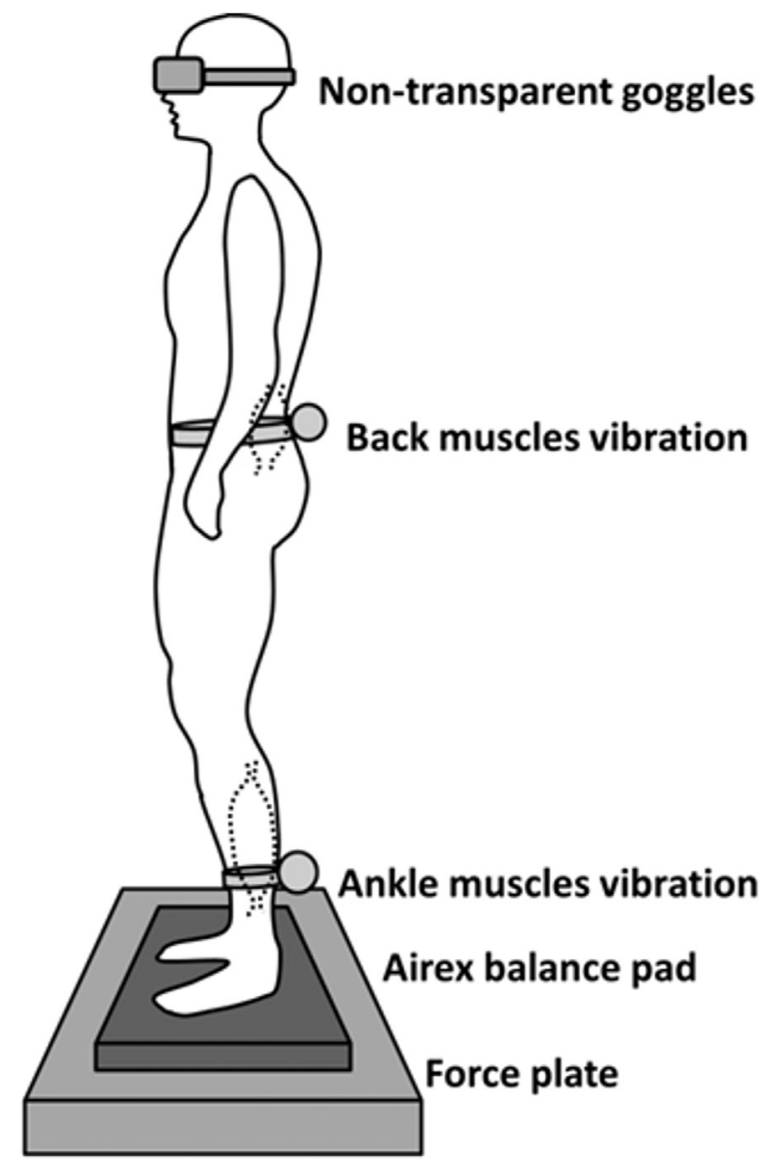

Fig. 2. Experimental setup to evaluate proprioceptive use during postural control.

afferents, evoking an illusion of muscle lengthening (Cordo et al., 2005; Roll and Vedel, 1982). When the central nervous system uses proprioceptive signals of the vibrated muscles for postural control, this causes a directional corrective center of pressure displacement. The amount of this center of pressure displacement represents the extent to which an individual makes use of the proprioceptive signals of the vibrated muscles to maintain the upright posture. Muscle vibrators (Maxon motors, Switzerland) were applied bilaterally over the triceps surae ('ankle') muscles and lumbar paraspinal ('back') muscles, as studied previously (Brumagne et al., 2008; Claeys et al., 2011, 2012, 2015; Janssens et al., 2015).

Participants were instructed to stand barefoot on the force plate, with their arms relaxed along the body and occluded vision. Two conditions were used: (1) upright standing on a stable support surface and (2) upright standing on an unstable support surface (Airex balance pad). On an unstable support surface, ankle proprioceptive signals are less reliable, which enforces reliance upon proximal proprioceptive signals (i.e., proprioceptive weighting), thereby highlighting proprioceptive deficits (Ivanenko et al., 1999). Within each condition, muscle vibration (15 s) was added bilaterally to the ankle muscles (trial 1) and to the back muscles (trial 2). The directional effect of muscle vibration on mean anterior-posterior center of pressure displacement was calculated. To provide information about proprioceptive dominance, a relative proprioceptive weighting ratio (RPW) was calculated using the following equation: $\mathrm{RPW}=$ (Abs ankle) $/$ (Abs ankle + Abs back $)$. 'Abs ankle' is the absolute value of the mean center of pressure displacement during ankle muscle vibration and 'Abs back' during back muscle vibration. An RPW score equal to 1 corresponds to $100 \%$ reliance on ankle muscle proprioception, whereas a score equal to 0 corresponds to $100 \%$ reliance on back muscle proprioception (Brumagne et al., 2008; Claeys et al., 2011, 2012, 2015; Janssens et al., 2015).
2.3.3.2. Sit-to-stand-to-sit (STSTS). Participants were instructed to sit barefoot on a stool on the force plate, with their arms relaxed along the body and vision occluded. The stool height was adjusted to create a $90^{\circ}$ angle in both hips and knees. After $15 \mathrm{~s}$ of usual sitting, the participants were asked to perform five STSTS movements, as fast as possible and with a full range of motion. The duration of this task, determined by the center of pressure displacement (Arcelus et al., 2009), was calculated (Simmonds, 1998).

\subsubsection{Secondary outcome measures}

The severity of back pain and leg pain were scored independently by NRS (Jensen et al., 1986), and the highest score of both was taken into analysis as the severity of pain score. Disability related to LBP was evaluated with the ODI-2 (Fairbank and Pynsent, 2000). The Tampa Scale for Kinesiophobia (TSK) from 17 ('low') to 68 ('high') was completed to identify the participants' fear of (re)injury following movements or activities (Kori et al., 1990).

\subsection{Statistical analysis}

A one-way analysis of variance (ANOVA) was used to examine differences in baseline characteristics between the two groups (Table 1). A between and within ANOVA was used to examine differences between subjects and within subjects. A post hoc test (Tukey) was performed to further analyze these results in detail. The statistical analysis was performed with Statistica 9.0 (Statsoft, USA). The level of significance was set at $P<0.05$.

\section{Results}

\subsection{Effect of surgical approach}

\subsubsection{Primary outcome measures}

3.1.1.1. Relative proprioceptive weighting ratio (RPW). When observing the relative use of ankle versus back muscles proprioceptive input 2 weeks after surgery (baseline), both the transmuscular and the paramedian group showed a dominant use of ankle proprioception on stable and unstable support surface, as shown by RPW ratios all above 0.5 . The transmuscular group switched to a more back proprioceptive use on unstable support surface 24 weeks after surgery, compared to 2 weeks $(0.22$ change; $P=0.001)$ and 8 weeks $(0.19$ change; $P=$ $0.003)$. This switch to a more back proprioceptive use was not observed in the paramedian group $(P>0.05)$. Furthermore, significant more back proprioceptive use was found on unstable, compared to stable support surface 2 weeks (both groups; $P<0.05$ ), 8 weeks (both groups; $P<0.05$ ), and 24 weeks (both groups; $P<0.005$ ) after surgery. Fig. 3 displays the RPW ratios of the transmuscular and paramedian group.

3.1.1.2. Sit-to-stand-to-sit (STSTS). Both the transmuscular and paramedian group needed significantly less time to perform five consecutive STSTS movements at 8 weeks (transmuscular: 10 s change; $P=0.003$ ) (paramedian: $6 \mathrm{~s}$ change; $P=0.012$ ) and 24 weeks (transmuscular: 14 s change; $P=0.001$ ) (paramedian: 11 s change; $P=0.001$ ) compared to 2 weeks after surgery. No difference in STSTS performance was found between the surgical approaches $(P>0.05)$. Fig. 4 displays the STSTS times of the transmuscular and paramedian group.

\subsubsection{Secondary outcome measures}

Compared to pre-surgery, severity of pain (NRS) declined significantly 2 weeks after surgery $(P<0.001)$, whereas ODI- 2 only declined after 8 weeks $(P<0.05)$ and TSK scores did not change up to 1 year after surgery $(P>0.05)$. No differences in secondary outcomes were found between the transmuscular and paramedian group $(P>0.05)$. 


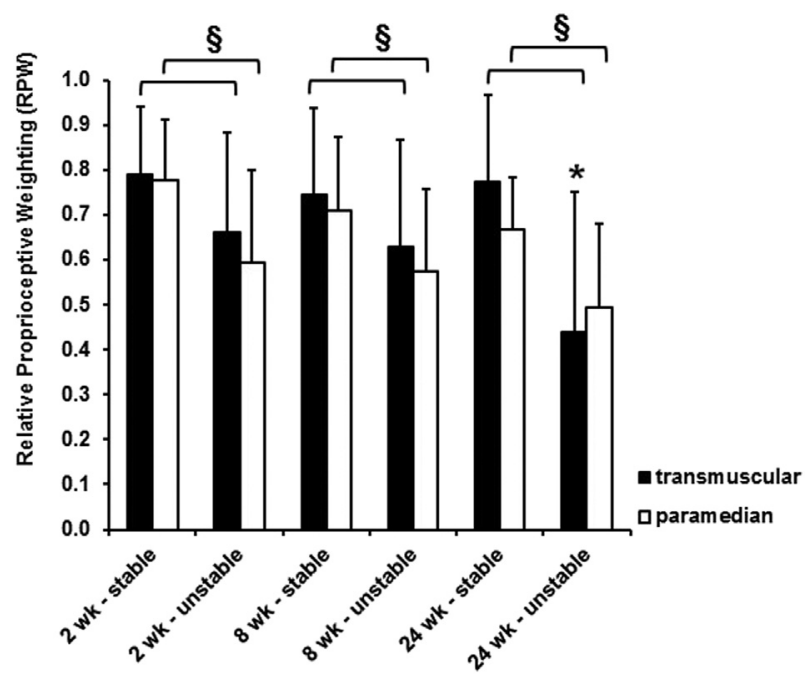

Fig. 3. Relative proprioceptive weighting ratios (mean and standard deviation) on stable and unstable support surface 2,8 , and 24 weeks after lumbar microdiscectomy in a transmuscular and paramedian surgery group. High values indicate high reliance on ankle muscles proprioceptive signals, whereas low values indicate high reliance on back muscles proprioceptive signals. *Significant difference $(P<0.05)$ compared to 2 and 8 weeks post surgery. ${ }^{\S}$ Significant difference $(P<0.05)$ between stable and unstable support surface.

Table 2 displays the secondary outcomes in the transmuscular and paramedian group.

\subsection{Effect of physiotherapy}

\subsubsection{Primary outcome measures}

3.2.1.1. Relative proprioceptive weighting ratio (RPW). When observing the relative use of ankle versus back muscles proprioceptive input 2 weeks after surgery (baseline), both the physiotherapy and usual care group showed a dominant use of ankle proprioception on stable and unstable support surface, as shown by RPW ratios all above 0.5 . The physiotherapy group switched to a more back proprioceptive use on unstable support surface 24 weeks after surgery, compared to 2 weeks $(0.24$ change; $P=0.001)$ and 8 weeks $(0.17$ change; $P=0.001)$. This was not observed in the usual care group $(P>0.05)$. Furthermore, significant more back proprioceptive use was found on unstable, compared to stable support surface 2 weeks (usual care; $P=0.002$ ), 8 weeks (physiotherapy; $P=0.018$ ) and 24 weeks (both groups; $P=0.001$ ) after surgery. Fig. 5 displays the RPW ratios of the physiotherapy and usual care group.

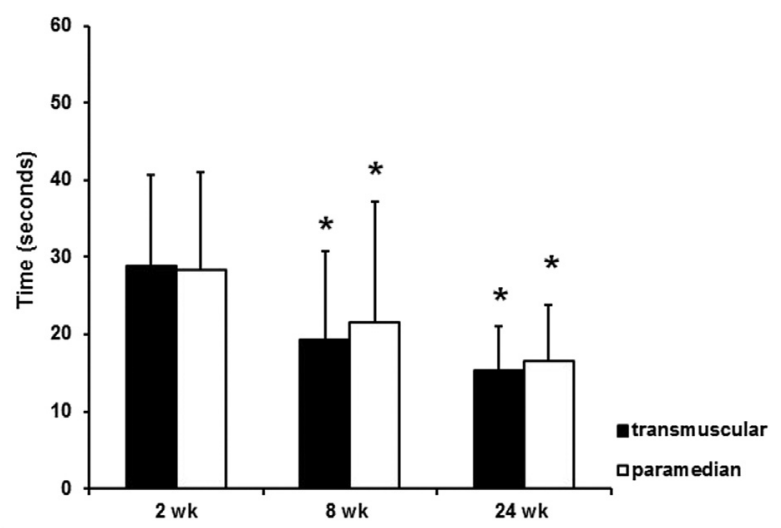

Fig. 4. Duration of five sit-to-stand-to-sit movements (mean and standard deviation) 2,8 , and 24 weeks after lumbar microdiscectomy in a transmuscular group and paramedian surgery group. *Significant difference $(P<0.05)$ compared to 2 weeks post surgery (baseline).
3.2.1.2. Sit-to-stand-to-sit (STSTS). Both the physiotherapy and usual care group needed significantly less time to perform five consecutive STSTS movements at 8 weeks (physiotherapy: $13 \mathrm{~s}$ change; $P=0.001$ ) (usual care: 4 s change; $P=0.021$ ) and 24 weeks (physiotherapy: 14 s change; $P=0.001$ ) (usual care: 11 s change; $P=0.001$ ), compared to 2 weeks after surgery. Although both groups improved over time, the physiotherapy group performed the STSTS task significantly faster at 8 weeks compared to the usual care group (14 (4) s vs. 26 (14) s) $(P=0.010)$. Fig. 6 displays the STSTS times of the physiotherapy and usual care group.

\subsubsection{Secondary outcome measures}

Compared to 2 weeks after surgery, severity of pain (NRS) did not change up to 1 year after surgery $(P>0.05)$, whereas ODI-2 declined after 8 weeks $(P<0.05)$. A trend suggested ODI- 2 to be lower in the physiotherapy compared to the usual care group at 24 weeks after surgery $(P=0.062)$. One year after surgery, TSK scores were declined $(P<0.05)$ and were significantly lower in the physiotherapy compared to the usual care group $(P=0.009)$. The global perceived effect of the intervention did not differ between both groups $(P=0.662)$, but the duration of work absence after 1 year was significantly lower in the physiotherapy group $(P=0.034)$. Three patients of the usual care developed a recurrence and needed second-time lumbar surgery, and none of the participants in the physiotherapy group needed resurgery. Table 3 displays the secondary outcomes in the physiotherapy and usual care group.

\section{Discussion}

After first-time lumbar microdiscectomy, patients exhibited a relatively low reliance on lumbosacral proprioceptive signals and high reliance on ankle proprioceptive signals to maintain balance. Six months after surgery, this was particularly pronounced in those who received paramedian, compared to transmuscular surgery. Individualized and early started physiotherapy after surgery facilitated increased reliance on lumbosacral proprioceptive signals 6 months after surgery, whereas this was not observed in the patients receiving usual care. Furthermore, already 8 weeks after surgery, patients following physiotherapy needed significantly less time to perform five consecutive STSTS movements, compared to those receiving usual care. However, the surgical approach did not affect STSTS performance. Severity of pain declined immediately after surgery, whereas LBP-related disability only declined after 8 weeks. Kinesiophobia was lower after physiotherapy compared to usual care, although the surgical approach did not influence this. To the author's knowledge, this is the first study evaluating proprioceptive use and related functionality in patients after lumbar microdiscectomy, and the effect of surgical approach and physiotherapy on it. It is important to notice that the described effects of physiotherapy are regardless of surgical technique, and the described effects of surgical approach are regardless of the (non-)physiotherapeutic intervention after surgery.

Two weeks after surgery, patients showed lower reliance on lumbosacral proprioceptive signals compared to ankle proprioceptive signals. After surgery, patients needed $29 \mathrm{~s}$ to perform five STSTS movements without vision, although healthy young individuals only needed $8 \mathrm{~s}$ (Claeys et al., 2012). Another study, with individuals with comparable moderate-to-high ODI scores after surgery, reported the need for $18 \mathrm{~s}$ after lumbar surgery but with vision (Kulig et al., 2009). Additionally, we found a comparable degree of down-weighting of lumbosacral proprioceptive signals and up-weighting of ankle proprioceptive signals in individuals with non-specific LBP without surgical history (Claeys et al., 2011), that affected STSTS performance (Claeys et al., 2012). Therefore, the current study suggests that the reliability of the lumbosacral proprioceptive signals still remains reduced after lumbar microdiscectomy. This may explain the long-term postural control deficits after lumbar surgery (Bouche et al., 2006; Leinonen et al., 2003). 
Table 2

Secondary outcome measures in the transmuscular and paramedian group.

\begin{tabular}{|c|c|c|c|c|c|c|c|}
\hline & & Pre-surgery & 2 weeks & 8 weeks & 24 weeks & 1 year & $P$-value (within) \\
\hline \multirow[t]{3}{*}{ NRS pain } & Transmuscular & $7.1(2.6)$ & $4.2(2.2)$ & $2.9(1.9)$ & $2.5(1.0)$ & $2.9(2.2)$ & $<0.001^{*}$ (pre vs. 2 weeks, 8 weeks, 24 weeks, 1 year) \\
\hline & Paramedian & $8.3(1.5)$ & $3.6(2.4)$ & $2.6(2.4)$ & $2.8(2.9)$ & $3.3(2.7)$ & $<0.001^{*}$ (pre vs. 2 weeks, 8 weeks, 24 weeks, 1 year) \\
\hline & $P$-value (between) & 0.309 & 0.800 & 0.895 & 0.956 & 0.700 & \\
\hline \multirow[t]{3}{*}{ ODI-2 (\%) } & Transmuscular & $23(10)$ & $28(16)$ & $20(16)$ & $14(11)$ & $16(15)$ & $<0.05^{*}$ (pre vs. 8 weeks, 24 weeks, 1 year) \\
\hline & Paramedian & $24(8)$ & $24(9)$ & $16(15)$ & $11(12)$ & $13(10)$ & $<0.01^{*}$ (pre vs. 8 weeks, 24 weeks, 1 year) \\
\hline & $P$-value (between) & 0.783 & 0.576 & 0.222 & 0.582 & 0.610 & \\
\hline \multirow[t]{3}{*}{ TSK } & Transmuscular & - & $44(6)$ & - & $42(5)$ & $37(5)$ & $>0.05$ \\
\hline & Paramedian & - & $43(7)$ & - & $38(5)$ & $37(4)$ & $>0.05$ \\
\hline & $P$-value (between) & - & 0.774 & - & 0.577 & 0.226 & \\
\hline \multirow[t]{3}{*}{ Work absence (days) } & Transmuscular & - & - & - & - & $104(79)$ & - \\
\hline & Paramedian & - & - & - & - & $155(71)$ & - \\
\hline & $P$-value (between) & - & - & - & - & 0.698 & \\
\hline \multirow{3}{*}{ Recurrence rate } & Transmuscular & - & - & - & - & 1 & - \\
\hline & Paramedian & - & - & - & - & 2 & - \\
\hline & $P$-value (between) & - & - & - & - & - & \\
\hline
\end{tabular}

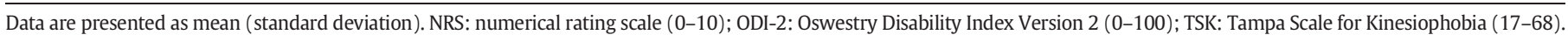
Significant $P$-values are marked with *.

The reduced lumbosacral proprioceptive use immediately after surgery was both visible after the traditional paramedian approach and after the minimally invasive transmuscular approach of surgery. Six months after surgery, the paramedian approach caused individuals to rely even less on lumbosacral proprioceptive during balance control, compared to 2 weeks after surgery. This surgically induced proprioceptive weighting can be explained by different mechanisms. First, the mechanoreceptors in the outer annulus of the intervertebral disc, spinal ligaments (Fagan et al., 2003; Roberts et al., 1995) and facet joint capsules (McLain and Pickar, 1998) have a proprioceptive function, and thus may be damaged during lumbar surgery. Second, the paramedian technique is accompanied by detachment of the trunk controlling muscles which may additionally damage proprioceptive endings in the muscles, i.e. the muscle spindles. Furthermore, the paramedian technique is associated with greater atrophy of the multifidus muscles compared to the transmuscular technique (Kim et al., 2008; Suwa et al., 2000), although the multifidus muscles account for two-thirds of the spinal control at level L4-L5 (Wilke et al., 1995). Additionally, the surgical incision, especially using the paramedian technique, creates muscle ischemia (Karikari and Isaacs, 2010), which may also reduce the proprioceptive reliability, as muscle spindles are



Fig. 5. Relative proprioceptive weighting ratios (mean and standard deviation) on stable and unstable support surface 2,8 , and 24 weeks after lumbar microdiscectomy in a physiotherapy group and usual care group. High values indicate high reliance on ankle muscles proprioceptive signals, whereas low values indicate high reliance on back muscles proprioceptive signals. *Significant difference $(P<0.05)$ compared to 2 and 8 weeks post surgery. ${ }^{\S}$ Significant difference $(P<0.05)$ between stable and unstable support surface. strongly perfused (Kokkorogiannis, 2004). Therefore, local ischemia might disturb muscle spindle function of the lumbosacral muscles, enforcing the use of ankle proprioceptive signals to maintain posture (Delliaux and Jammes, 2006). Third, muscle spindle function can be diminished by pain (Capra and Ro, 2000), although pain in contrast to disability (evaluated by ODI-2) was already diminished immediately after surgery. Finally, the patients reported a high degree of kinesiophobia after surgery, according to reference values (Vlaeyen et al., 1995). This can be confirmed by Svensson et al. (2011), and these high TSK scores seem to be based on fear of moving wrong would undo the surgery (Williamson et al., 2008). Fear of movement in individuals with LBP is associated with trunk muscle stiffness (Karayannis et al., 2013). This stiffness creates short-term protection of the spine (Hodges et al., 2013), but appears to be maladaptive in the long run, since flexible spinal movement is critical in maintaining postural control (Mok and Hodges, 2013), and in optimal STSTS performance (Dubost et al., 2005). This in turn may explain the dominant ankle proprioceptive use and the poor STSTS performance after lumbar microdiscectomy. Taken together, the less damaging effect of transmuscular lumbar surgery techniques on proprioceptive and functional aspects on the long-term might have been overlooked in the past. The present study is the first to point in that direction.

We observed a higher reliance on lumbosacral proprioceptive input and lower reliance on ankle proprioceptive input 6 months after surgery in the group who received physiotherapy. High ankle proprioceptive reliance has recently been recognized as a risk factor for future LBP (Claeys et al., 2015). This factor can now be suggested as a reversible parameter,



Fig. 6. Duration of five sit-to-stand-to-sit movements (mean and standard deviation) 2, 8 , and 24 weeks after lumbar microdiscectomy in a physiotherapy group and usual care group. *Significant difference $(P<0.05)$ compared to 2 weeks post surgery (baseline). "Significant difference $(P<0.05)$ between groups. 
Table 3

Secondary outcome measures in the physiotherapy and usual care group.

\begin{tabular}{|c|c|c|c|c|c|c|c|}
\hline & & Pre-surgery & 2 weeks & 8 weeks & 24 weeks & 1 year & $P$-value (within) \\
\hline \multirow[t]{3}{*}{ NRS pain } & Physiotherapy & $7.6(3.2)$ & $3.3(2.5)$ & $2.7(1.9)$ & $1.8(1.3)$ & $2.1(2.1)$ & $<0.001^{*}$ (pre vs. 2 weeks, 8 weeks, 24 weeks, 1 year) \\
\hline & Usual care & $7.6(3.2)$ & $4.5(1.9)$ & $2.8(2.4)$ & $3.4(2.6)$ & $3.8(2.6)$ & $<0.001^{*}$ (pre vs. 2 weeks, 8 weeks, 24 weeks, 1 year) \\
\hline & $P$-value (between) & 0.667 & 0.489 & 0.602 & 0.241 & 0.088 & \\
\hline \multirow[t]{3}{*}{ ODI-2 (\%) } & Physiotherapy & $25(6)$ & $26(14)$ & $17(15)$ & $9(8)$ & $15(15)$ & $<0.05^{*}$ (pre vs. 8 weeks, 24 weeks, 1 year) \\
\hline & Usual care & $22(11)$ & $26(13)$ & $19(16)$ & $16(12)$ & $16(11)$ & $<0.01^{*}$ (pre vs. 8 weeks, 24 weeks, 1 year) \\
\hline & $P$-value (between) & 0.584 & 0.427 & 0.516 & 0.062 & 0.629 & \\
\hline \multirow[t]{3}{*}{ TSK } & Physiotherapy & - & $42(6)$ & - & $43(5)$ & $36(2)$ & $<0.05^{*}$ ( 2 weeks, 24 weeks vs. 1 year) \\
\hline & Usual care & - & $44(7)$ & - & $38(5)$ & $38(5)$ & $>0.05$ ( 2 weeks, 24 weeks vs. 1 year) \\
\hline & $P$-value (between) & - & 0.801 & - & 0.524 & $0.009^{*}$ & \\
\hline \multirow[t]{3}{*}{ Global perceived effect } & Physiotherapy & - & - & - & - & $2.7(1.6)$ & - \\
\hline & Usual care & - & - & - & - & $2.6(1.3)$ & - \\
\hline & $P$-value (between) & - & - & - & - & 0.662 & \\
\hline \multirow[t]{3}{*}{ Work absence (days) } & Physiotherapy & - & - & - & - & $69(38)$ & - \\
\hline & Usual care & - & - & - & - & $143(84)$ & - \\
\hline & $P$-value (between) & - & - & - & - & $0.034^{*}$ & \\
\hline \multirow[t]{3}{*}{ Recurrence rate } & Physiotherapy & - & - & - & - & 0 & - \\
\hline & Usual care & - & - & - & - & 3 & - \\
\hline & $P$-value (between) & - & - & - & - & - & \\
\hline
\end{tabular}

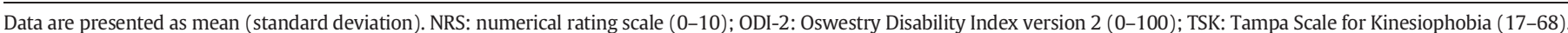
Significant $P$-values are marked with *.

although it must be noticed that the risk factor was studied in a nonspecific LBP population without surgical history (Claeys et al., 2015). The improved proprioceptive use after physiotherapy might be caused by a more optimal activation of the multifidus muscles. Hebert et al. (2010) observed already decreased intramuscular fat in the multifidus after 8 weeks of physiotherapy following lumbar microdiscectomy. Several studies demonstrated that motor control exercises improve multifidus muscles function and postural control, both by changes on a peripheral (Hides et al., 1996; Tsao and Hodges, 2008) and central level (Tsao et al., 2010). By verifying the possibility to reverse the suboptimal proprioceptive use during postural control in lumbar surgery patients through physiotherapy, our results suggest that the lack of motor control contributes to the reduced functionality after surgery. The impact of physiotherapy on functionality was shown by a faster STSTS performance in the physiotherapy group, already 8 weeks after surgery, and a trend toward a lower ODI- 2 score after 1 year. The improvement in proprioceptive use might have determined the faster STSTS performance since this latter task requires postural control (Lord et al., 2002). Furthermore, the association between proprioceptive use and STSTS performance was already observed in non-specific LBP patients (Claeys et al., 2012). However, we do not have direct proof of this causal relationship in the current study.

Although pain already decreased remarkably by lumbar microdiscectomy, regardless of the approach, the impact of LBP on functionality improved only after an additional physiotherapy program. Our advice for early active physiotherapy after lumbar microdiscectomy is supported by the fact that physiotherapy elicited early STSTS improvement and diminished kinesiophobia, whereas the transmuscular approach could not reveal improvements on functional parameters. This latter can also be explained by the fact that the clinical added value of less invasive surgical techniques of lumbar microdiscectomy is recently found questionable (Kamper et al., 2014).

The positive effect of physiotherapy on functional parameters such as STSTS, ODI, and TSK was also reflected in the shorter duration of work absence in the physiotherapy group, compared to the usual care group. Indeed, lower ODI scores are associated with shorter work absence following lumbar disc herniation (Puolakka et al., 2008). For re-surgery, no related factors (age, gender, preoperative symptoms, physical activity, or employment) are previously defined; however, physiotherapy was not evaluated in that study (Häkkinen et al., 2007).

An important limitation of this study was the small sample size. As a consequence, it was not possible to calculate a potential interaction effect (physiotherapy/usual care $\mathrm{x}$ transmuscular/paramedian technique), based the a priori power calculation. Nevertheless, as a consistent within-group effect was observed, this proof-of-principle study suggests that reduced proprioceptive use can be an underlying mechanism in the residual complaints after lumbar microdiscectomy. However, it must be kept in mind while interpreting the results that the effects of physiotherapy are regardless of surgical technique, and the effects of surgical approach are regardless of (non)physiotherapy. A second limitation is the lack of a pre-surgery evaluation of proprioceptive use and STSTS performance. Due to pre-surgery disability, this evaluation was not performed. However, it would have provided more insight into the effect of the surgical intervention itself, free from the existing LBP, on the outcomes. Moreover, a matched control group without lumbar surgical history would have improved the study design. A prospective study with a large sample size must reveal whether proprioceptive measures can select patients at risk of residual complaints after lumbar surgery (den Boer et al., 2010) and, consequently, improve targeted care for lumbar microdiscectomy patients (Costa et al., 2013; McGregor et al., 2006; van der Windt and Dunn, 2013).

\section{Conclusion}

Two weeks after first-time lumbar microdiscectomy, patients show a low reliance on lumbosacral proprioceptive signals and high reliance on ankle proprioceptive signals to maintain balance, a slow STSTS performance, and moderate-to-high disability. Six months after surgery, this maladaptive proprioceptive use was particularly pronounced when using the paramedian compared to the transmuscular surgical technique. However, early individualized active physiotherapy enabled to increase the reliance on lumbosacral proprioceptive signals, leading to an earlier improvement in the performance of STSTS and lower kinesiophobia. Therefore, lumbosacral proprioceptive impairments may play an important and modifiable factor underlying disability after lumbar microdiscectomy and justifies further study to target this in a larger sample and long-term follow-up.

\section{Funding}

This work was supported by the Research Foundation Flanders (FWO) (postdoctoral fellowship Lotte Janssens), the Agency for Innovation by Science and Technology-Flanders (IWT) (PhD fellowship Nina Goossens), and by Stryker and Medtronic (administrative staff support). The funders have no conflict of interest in the study design, in the collection, analysis, and interpretation of data; in the writing of the manuscript; and in the decision to submit the manuscript for publication. 


\section{Conflict of interest}

The authors declare no conflict of interest in the study.

\section{Acknowledgements}

We thank Dominike Bruyninckx, Ann Spriet, Tessa Maeckelberghe, and Dr. Peter Van Wambeke for their important contribution to the study. The authors are grateful to the study volunteers for their participation.

\section{References}

Airaksinen, O. Brox, J.I. Cedraschi, C., et al., 2006. COST B13 Working Group on Guidelines for Chronic Low Back Pain. Chapter 4. European guidelines for the management of chronic nonspecific low back pain. Eur Spine J 15, S192-S300

Arcelus, A., Herry, C.L., Goubran, R.A., Knoefel, F., Sveistrup, H., Bilodeau, M., 2009. Determination of sit-to-stand transfer duration using bed and floor pressure sequences. IEEE Trans Biomed Eng 56, 2485-2492. http://dx.doi.org/10.1109/TBME.2009.2026733.

Bouche, K., Stevens, V., Cambier, D., Caemaert, J., Danneels, L., 2006. Comparison of postural control in unilateral stance between healthy controls and lumbar discectomy patients with and without pain. Eur Spine J 15, 423-432.

Brumagne, S., Janssens, L., Knapen, S., Claeys, K., Suuden-Johanson, E., 2008. Persons with recurrent low back pain exhibit a rigid postural control strategy. Eur Spine J 17, 1177-1184. http://dx.doi.org/10.1007/s00586-008-0709-7.

Capra, N.F., Ro, J.Y., 2000. Experimental muscle pain produces central modulation of proprioceptive signals arising from jaw muscle spindles. Pain 86, 151-162.

Carragee, E.J., Han, M.Y., Yang, B., Kim, D.H., Kraemer, H., Billys, J., 1999. Activity restrictions after posterior lumbar discectomy. A prospective study of outcomes in 152 cases with no postoperative restrictions. Spine 24, 2346-2351

Claeys, K., Brumagne, S., Dankaerts, W., Kiers, H., Janssens, L., 2011. Decreased variability in postural control strategies in young people with non-specific low back pain is associated with altered proprioceptive reweighting. Eur J Appl Physiol 111, 115-123. http://dx.doi.org/10.1007/s00421-010-1637-x.

Claeys, K., Dankaerts, W., Janssens, L., Brumagne, S., 2012. Altered preparatory pelvic control during the sit-to-stance-to-sit movement in people with non-specific low back pain. J Electromyogr Kinesiol 22, 821-828. http://dx.doi.org/10.1016/j.jelekin.2012. 04.007 .

Claeys, K., Brumagne, S., Janssens, L., Pijnenburg, M., Goossens, N., Brumagne, S., 2015. Young individuals with a more ankle-steered proprioceptive control strategy may develop mild non-specific low back pain. J Electromyogr Kinesiol 25, 329-338. http://dx.doi.org/10.1016/j.jelekin.2014.10.013.

Cordo, P... Gurfinkel, V.S., Brumagne, S., Flores-Vieira, C., 2005. Effect of slow, small movement on the vibration-evoked kinesthetic illusion. Exp Brain Res 167, 324-333.

Costa, L.D., Koes, B.W., Pransky, G., Borkan, J., Maher, C.G., Smeets, R.J., 2013. Primary care research priorities in low back pain: an update. Spine 38, 148-156. http://dx.doi.org/ 10.1097/BRS.0b013e318267a92f.

Dall, P.M., Kerr, A., 2010. Frequency of the sit to stand task: an observational study of freeliving adults. Appl Ergon 41, 58-61. http://dx.doi.org/10.1016/j.apergo.2009.04.005.

Delliaux, S., Jammes, Y., 2006. Effects of hypoxia on muscle response to tendon vibration in humans. Muscle Nerve 34, 754-761.

den Boer, J.J., Oostendorp, R.A., Evers, A.W., Beems, T., Borm, G.F., Munneke, M., 2010. The development of a screening instrument to select patients at risk of residual complaints after lumbar disc surgery. Eur J Phys Rehabil Med 46, 497-503.

Dubost, V., Beauchet, O., Manckoundia, P., Herrmann, F., Mourey, F., 2005. Decreased trunk angular displacement during sitting down: an early feature of aging. Phys Ther 85, 404-412.

Fagan, A., Moore, R., Vernon Roberts, B., Blumbergs, P., Fraser, R., 2003. ISSLS prize winner. The innervation of the intervertebral disc: a quantitative analysis. Spine 28, 2570-2576.

Fairbank, J.C., Pynsent, P.B., 2000. The Oswestry Disability Index. Spine 25, 2940-2952.

Häkkinen, A., Kiviranta, I., Neva, M.H., Kautiainen, H., Ylinen, J., 2007. Reoperations after first lumbar disc herniation surgery; a special interest on residives during a 5-year follow-up. BMC Musculoskelet Disord 8, 2

Hebert, J.J., Marcus, R.L., Koppenhaver, S.L., Fritz, J.M., 2010. Postoperative rehabilitation following lumbar discectomy with quantification of trunk muscle morphology and function: a case report and review of the literature. J Orthop Sports Phys Ther 40 402-412. http://dx.doi.org/10.2519/jospt.2010.3332.

Hides, J.A., Richardson, C.A., Jull, G.A., 1996. Multifidus muscle recovery is not automatic after resolution of acute, first-episode low back pain. Spine 21, 2763-2769.

Hodges, P.W., Coppieters, M.W., MacDonald, D., Cholewicki, J., 2013. New insight into motor adaptation to pain revealed by a combination of modelling and empirical approaches. Eur J Pain 17, 1138-1146. http://dx.doi.org/10.1002/j.1532-2149.2013. 00286.X.

Ivanenko, Y.P., Talis, V.L., Kazennikov, O.V., 1999. Support stability influences postura responses to muscle vibration in humans. Eur J Neurosci 11, 647-654

Jacobs, J.V., Yaguchi, C., Kaida, C., et al., 2011a. Effects of experimentally induced low back pain on the sit-to-stand movement and electroencephalographic contingent negative variation. Exp Brain Res 215, 123-134. http://dx.doi.org/10.1007/s00221-011-2880z.

Jacobs, W.C., van Tulder, M., Arts, M., et al., 2011b. Surgery versus conservative management of sciatica due to a lumbar herniated disc: a systematic review. Eur Spine 20, 513-522. http://dx.doi.org/10.1007/s00586-010-1603-7.
Janssens, L., McConnell, A.K., Pijnenburg, M., Claeys, K., Goossens, N., Lysens, R., Troosters, T., Brumagne, S., 2015. Inspiratory muscle training affects proprioceptive use and low back pain. Med Sci Sports Exerc 47 (1), 12-19. http://dx.doi.org/10.1249/MSS. 0000000000000385

Jensen, M.P., Karoly, P., Braver, S., 1986. The measurement of clinical pain intensity: a comparison of six methods. Pain 27, 117-126.

Kamper, S.J., Ostelo, R.W., Rubinstein, S.M., Nellensteijn, J.M., Peul, W.C., Arts, M.P., van Tulder, M.W., 2014. Minimally invasive surgery for lumbar disc herniation: a systematic review and meta-analysis. Eur Spine J 23 (5), 1021-1043. http://dx.doi.org/10. 1007/s00586-013-3161-2.

Karayannis, N.V., Smeets, R.J., van den Hoorn, W., Hodges, P.W., 2013. Fear of movement is related to trunk stiffness in low back pain. PLoS One 8, e67779.

Karikari, I.O., Isaacs, R.E., 2010. Minimally invasive transforaminal lumbar interbody fusion: a review of techniques and outcomes. Spine 35, S294-S301. http://dx.doi.org/ 10.1097/BRS.0b013e3182022ddc.

Kim, K., Isu, T., Sugawara, A., Matsumoto, R., Isobe, M., 2008. Comparison of the effect of 3 different approaches to the lumbar spinal canal on postoperative paraspinal muscle damage. Surg Neurol 69, 109-113. http://dx.doi.org/10.1016/j.surneu.2007. 04.021.

Kokkorogiannis, T., 2004. Somatic and intramuscular distribution of muscle spindles and their relation to muscular angiotypes. J Theor Biol 229, 263-280.

Kori, K.S., Miller, R.P., Todd, D.D., 1990. Kinesiophobia: a new view of chronic pain behaviour. Pain 3, 35-43.

Kulig, K., Beneck, G.J., Selkowitz, D.M., et al., 2009. An intensive, progressive exercise program reduces disability and improves functional performance in patients after single-level lumbar microdiskectomy. Phys Ther 89, 1145-1157. http://dx.doi.org/ 10.2522/ptj.20080052.

Leinonen, V., Kankaanpää, M., Luukkonen, M., et al., 2003. Lumbar paraspinal muscle function, perception of lumbar position, and postural control in disc herniationrelated back pain. Spine $28,842-848$.

Lord, S.R., Murray, S.M., Chapman, K., Munro, B., Tiedemann, A., 2002. Sit-to-stand performance depends on sensation, speed, balance, and psychological status in addition to strength in older people. J Gerontol A Biol Sci Med Sci 57, M539-M543.

Loupasis, G.A., Stamos, K., Katonis, P.G., Sapkas, G., Korres, D.S., Hartofilakidis, G., 1999. Seven- to 20-year outcome of lumbar discectomy. Spine 24, 2313-2317.

McGregor, A.H., Dicken, B., Jamrozik, K., 2006. National audit of post-operative management in spinal surgery. BMC Musculoskelet Disord 7, 47.

McLain, R.F., Pickar, J.G., 1998. Mechanoreceptor endings in human thoracic and lumbar facet joints. Spine 23, 168-173.

Millisdotter, M., Strömqvist, B., 2007. Early neuromuscular customized training after surgery for lumbar disc herniation: a prospective controlled study. Eur Spine J $16,19-26$.

Mok, N.W., Hodges, P.W., 2013. Movement of the lumbar spine is critical for maintenance of postural recovery following support surface perturbation. Exp Brain Res 231, 305-313. http://dx.doi.org/10.1007/s00221-013-3692-0.

Oosterhuis, T., Costa, L.O., Maher, C.G., de Vet, H.C., van Tulder, M.W., Ostelo, R.W., 2014. Rehabilitation after lumbar disc surgery. Cochrane Database Syst Rev 3, CD003007. http://dx.doi.org/10.1002/14651858.CD003007.pub3.

Puolakka, K., Ylinen, J., Neva, M.H., Kautiainen, H., Häkkinen, A., 2008. Risk factors for back pain-related loss of working time after surgery for lumbar disc herniation: a 5-year follow-up study. Eur Spine J 17, 386-392.

Roberts, S., Eisenstein, S.M., Menage, J., Evans, E.H., Ashton, I.K., 1995. Mechanoreceptors in intervertebral discs. Morphology, distribution, and neuropeptides. Spine 20, 2645-2651.

Roll, J.P., Vedel, J.P., 1982. Kinaesthetic role of muscle afferents in man, studied by tendon vibration and microneurography. Exp Brain Res 47, 177-190.

Shacklock, M., 1995. Neurodynamics. Physiotherapy 81, 9-16.

Shum, G.L., Crosbie, J., Lee, R.Y., 2009. Energy transfer across the lumbosacral and lowerextremity joints in patients with low back pain during sit-to-stand. Arch Phys Med Rehabil 90, 127-135. http://dx.doi.org/10.1016/j.apmr.2008.06.028.

Simmonds, M.J., 1998. Psychometric characteristics and clinical usefulness of physical performance tests in patients with low back pain. Spine 23, 2412-2421.

Sipko, T., Chantsoulis, M., Kuczyński, M., 2010. Postural control in patients with lumbar disc herniation in the early postoperative period. Eur Spine J 19, 409-414. http:// dx.doi.org/10.1007/s00586-009-1082-x.

Sullivan, M.J.L., Bishop, S.R., Pivik, J., 1995. The pain catastrophizing scale: development and validation. Psychol Assess 7, 524-532.

Suwa, H., Hanakita, J., Ohshita, N., Gotoh, K., Matsuoka, N., Morizane, A., 2000. Postoperative changes in paraspinal muscle thickness after various lumbar back surgery procedures. Neurol Med Chir 40, 151-154 (discussion 154-5).

Svensson, G.L., Lundberg, M., Ostgaard, H.C., Wendt, G.K., 2011. High degree of kinesiophobia after lumbar disc herniation surgery: a cross-sectional study of 84 patients. Acta Orthop 82, 732-736. http://dx.doi.org/10.3109/17453674.2011. 636674.

Tsao, H., Hodges, P.W., 2008. Persistence of improvements in postural strategies following motor control training in people with recurrent low back pain. J Electromyogr Kinesiol 18, 559-567.

Tsao, H., Galea, M.P., Hodges, P.W., 2010. Driving plasticity in the motor cortex in recurrent low back pain. Eur J Pain 14, 832-839. http://dx.doi.org/10.1016/j.ejpain.2010. 01.001

van der Windt, D.A., Dunn, K.M., 2013. Low back pain research-future directions. Best Pract Res Clin Rheumatol 27 (5), 699-708. http://dx.doi.org/10.1016/j.berh.2013.11. 001

Vlaeyen, J.W., Kole-Snijders, A.M., Boeren, R.G., van Eek, H., 1995. Fear of movement/(re)injury in chronic low back pain and its relation to behavioral performance. Pain 62 , 363-372. 
Waddell, G., Newton, M., Henderson, I., Somerville, D., Main, C.J., 1993. A fear-avoidance beliefs questionnaire (FABQ) and the role of fear-avoidance beliefs in chronic low back pain and disability. Pain 52, 157-168.

Wilke, H.J., Wolf, S., Claes, L.E., Arand, M., Wiesend, A., 1995. Stability increase of the lumbar spine with different muscle groups. A biomechanical in vitro study. Spine 20, 192-198.

Williamson, E., White, L., Rushton, A., 2007. A survey of post-operative management for patients following first time lumbar discectomy. Eur Spine J 16, 795-802.
Williamson, J., Bulley, C., Coutts, F., 2008. What do patients feel they can do following lumbar microdiscectomy? A qualitative study. Disabil Rehabil 30, 1367-1373. http://dx.doi.org/10.1080/09638280701639915.

Zigmond, A.S., Snaith, R.P., 1983. The hospital anxiety and depression scale. Acta Psychiatr Scand 67, 361-370. 